\title{
Abandoning Creativity: The evolution of creative ideas in engineering design course projects
}

\author{
Elizabeth Starkey, Christine A. Toh \\ Department of Industrial \& Manufacturing Engineering, \\ Pennsylvania State University, University Park, PA 16802, USA \\ Scarlett R. Miller \\ School of Engineering Design, Technology, and Professional Programs, Pennsylvania \\ State University, University Park, PA 16803, USA
}

Corresponding Author, Scarlett R. Miller

phone: 1-814-863-4143, fax: 1-814-863-7229, email: scarlettmiller@psu.edu

\begin{abstract}
Creativity training has been widely integrated into engineering education as a means to prepare students to be an innovative force in design industry. However, much of this research has focused on training students to be creative idea generators, with limited attention to what happens after this generation. Thus, the current study was developed to understand how creative ideas are promoted or filtered throughout the design process in order to focus our educational efforts. In order to accomplish this, an 8-week study with 130 engineering students was conducted. Our results point to the reduction in creativity throughout the design process and student abandonment of novel concepts. We also expose the influence of the design task on student creativity.
\end{abstract}

Keywords: creativity; idea generation; concept selection; design education; engineering design 
Training our future engineers to be creative is an important and often required component of engineering education (Canadian Engineering Accreditation Board, 2014; Dym, et al., 2005; International Engineering Alliance, 2013). This is due in part to the fact that industry is placing a larger emphasis on recruiting creative engineers because of the impact of innovation on economic and societal success (McAloone, 2007). Since product success can be linked to early ideas (Goldenberg, et al., 2001), research in engineering education has focused on creativity during idea generation (Daly, et al., 2012; Linsey, et al., 2011; Vargas Hernandez, et al., 2014). While effective concept generation is imperative for innovation (Daly, et al., 2012), little research has explored what happens after creative ideas are developed in engineering courses.

What we do know is that the creative potential built up during idea generation is often lost throughout the design process because people do not know how to properly evaluate and select creative ideas (Harms \& Van der Zee, 2013). In addition, researchers have shown that people avoid rather than seek radical innovations during the design process (Goldenberg, et al., 2001). This research implies that while the availability of creative ideas is necessary for innovation to occur, idea generation is only a part of the innovation process and merely developing creative ideas is an insufficient condition for innovation (Nijstad \& De Dreu, 2002). Therefore, while training engineering students to develop creative ideas is an important component of engineering education, it is essential that we understand how these creative ideas progress or are filtered out throughout the design process, and what factors can influence this process. Without this knowledge, we do not know where we should focus our creativity training efforts. 
In light of this inherent research gap, the current study was developed to understand how the novelty, quality, and overall creativity of student design teams' ideas change throughout the design process and what variables mediate this process. In order to answer these questions, an empirical study was conducted with 136 first-year engineering design students over the course of an 8-week (half-semester) design project in an engineering design course. The results of this study contributes new knowledge on the relationship between design outputs and the flow of creative ideas throughout the design process in an engineering design class and provides recommendations for how to focus engineering pedagogy to increase student creative outputs. Prior related research that motivate this research study are presented in the following sections.

\section{Background \& Motivation}

Although not focused on the flow of creative ideas throughout the design process, there has been research focused on creativity in engineering education. This section serves to highlight research in this area and lay the groundwork for the current study by starting with a broad overview of creativity in engineering education and narrowing in on moderating variables such as the influence of task selection.

\subsection{Creative Idea Development in Engineering Design Education}

Engineering educators have devoted much time and attention to integrating creativity training into the engineering curricula (Charyton, 2014). The thinking is that by teaching students the design process, individuals will be better able to connect and energize innovation processes in industry (Brown, 2008; Dym, et al., 2005). While there are many stages to the design process including idea generation, idea screening 
(selection), idea development and solution verification (Zhang, et al., 2015), engineering design research has focused largely on understanding how to improve student idea generation capacities (see for example (Daly, et al., 2012; Linsey, et al., 2011; Vargas Hernandez, et al., 2014). This is due in part to the fact that while not every idea qualifies as creative, every creative outcome can be traced back to the good ideas that started it off (Goldschmidt \& Tatsa, 2005). In fact, research has shown that the success or failure of an innovative product can be linked to the very early stages of an idea's emergence (Goldenberg, et al., 2001) and a consumer's purchase intent can be linked to the quality of the 'raw idea' (Kornish \& Ulrich, 2014).

While research in this area has led to a better understanding of how to increase student idea generation capacities, the underlying assumption of this research is that successful innovation depends on creative idea generation. However, there has been mixed findings on the impact of idea generation on the quality of the final creative solution; while Kazakci, et al. (2015) found that the number of original ideas generated by a team is not necessarily a predictor of high performance, Zhang, et al. (2015) found that idea generation had a significant impact on the quality of the final creative solution. These findings suggest that while the availability of creative ideas is necessary for innovation to occur, idea generation is only a part of the innovation process and merely developing creative ideas is an insufficient condition for innovation (Nijstad \& De Dreu, 2002). However, no study to date has explored if, or how, creative idea generation relates to the quality the final creative solution in engineering education.

However, since we know that good ideas lead to a greater level of success, there is great value in the accurate selection of ideas throughout the design process (Kornish \& 
Ulrich, 2014). This means in order to increase the potential for innovation, good ideas must be appropriately selected and managed during the fuzzy front end of the design process (Ende, et al., 2014). During this convergence process, individuals and teams must decide which (raw) ideas to drop and which to further develop by assessing their potential to be developed into a successful new product (Florén \& Frishammar, 2012; Kim \& Wilemon, 2002; Koch \& Leitner, 2008). While it may seem likely that one's ability to generate creative ideas would be related to their tendency to select creative ideas during the concept selection process, a recent study found that these two skills were unrelated ( Toh \& Miller, 2014). In other words, a person who is able to generate many creative ideas does not necessarily have a higher tendency to select creative concepts during the concept selection process.

The fact that people desire but often reject creativity (Mueller, et al., 2014) has be linked to the risk associated with endorsing novel ideas (E. F. Rietzschel, et al., 2010; Rubenson \& Runco, 1995) and the uncertainty regarding the success and social approval of their decisions (Moscovici, 1976). A similar effect has been found in engineering education, where it has been shown that students rarely discuss creativity during concept selection but instead focus on the technical feasibility of the idea set (Toh \& Miller, 2015). This means that opportunities for successful new product development may be eliminated at the very beginning of the design process (Eling, et al., 2015). While researchers have reported that individuals and groups rarely select their best ideas (Faure, 2004; Putman \& Paulus, 2009), little research has been conducted to explore the impact of the creativity of ideas a team selects during concept selection and the creativity of their final design outcome. This is important because without this knowledge we do not know 
if we should gear education towards helping students better assess designs during this process.

Another factor to consider is what happens after an idea is selected. For example, after an idea is selected, engineering designers often go through prototyping activities in order to detect errors and weaknesses in product design (Römer, et al., 2001). Prototyping is a key component of engineering design education (Yang, 2005) because it has been linked to improved design outcomes (Elsen, et al., 2012), improved functionality of the final design (Viswanathan, 2012), and an improved ability to meet client requirements (Jang \& Schunn, 2011). While prototyping can help designers identify problems and make changes to their design, it can also negatively impact designers by creating a "lock in effect", keeping designers from freely changing their designs when a new need or

constraint is identified (Kiriyama \& Yamamoto, 1998). In addition, researchers have shown that it is mostly the team process surrounding prototyping that impacts the quality of the final prototype (Vetterli, et al., 2014). Because of the impact of prototyping and team developmental efforts on final design deliverables, it is not clear if training student's to generate or select creative ideas is sufficient for helping students ultimately develop creative solutions in engineering design courses or if there are some other mediating factors influencing the final design outputs. This paper aims to fill this research void.

\subsection{The impact of the design task in engineering education}

In addition to exploring how the creativity in the fuzzy front end of the design process impacts the creativity of the final design output, it's also important to consider other factors that might moderate this relationship. One potential moderator is the design task being explored because design educators tends to employee a wide range of open- 
ended and ill-structured problems in education in order to nurture creative problemsolving skills (Felder, 1987; Ghosh, 1993). Ill-structured problems are problems in which there are multiple 'correct' solutions (Jonassen, 1997; Stokes, 2005). While many universities have adopted the use of these open-ended design problems, a recent study exposed that the type of design task being explored can greatly influence ideation creativity through both a between- and within-subject study (Fabien Durand, 2015). This was found to be true for design tasks that were subjectively intended to be 'equivalent'. Interestingly, Kershaw, et al. (2015) also found that the semester in which an engineering student is given a particular design problem can affect the creativity of the generated ideas. While these studies illustrate that the type, and timing, of a design problem in engineering education may impact student creativity training (see discussion in (Kremer, et al., 2011)), few studies have explored the impact of the design task being explored in the phases following idea generation. Therefore, we do not know how these varying problem types promote or inhibit creative idea development in engineering education.

While not studied in an engineering context, research in psychology (Hackman, 1968; Kabanoff \& O'brien, 1979; Kelly \& McGrath, 1985; Reiter-Palmon, et al., 2009) and management (Jia, et al., 2013; Karni \& Shalev, 2004; Leenders, et al., 2003) has shown that the type of problem being explored can significantly impact the quality and originality of the final design. In addition, Rietzschel, et al. (2008) found that the scope of the problem impacted idea generation with a narrower problem scope leading the production of more original ideas. However, there was no impact of task on idea selection. This may be due in part to the type of constraints included in a given design task. 
On a high level, design problem constraints can be categorized as either abstract (e.g. low cost) or concrete (e.g. cost less than \$10) (Onarheim \& Wiltschnig, 2010). These constraints can then be further sub-categorized into one ore more of the following dimensions: timing, flexibility, importance, source, domain, and/or purpose (Onarheim, 2012). Since it is impossible to kindle creativity from nothing (Rosenman \& Gero, 1993), design constraints are a necessary condition for creativity (Horowitz, 1999). However, there have been mixed findings on the exact relationship between constraints and creativity. For example, while some believe that constraints limit creativity due to the limited size of the possible solution space (Jonassen, 1997), others have found a linear correlation between creativity and constraint (Joyce, 2009). In this way, constraints can both facilitate and limit creativity (Negus \& Pickering, 2004; Stokes, 2008). However, there is little empirical work investigating the impact of constraint on creativity (Joyce, 2009), especially in an engineering education context. Therefore, the current work was developed to respond to this research gap.

\section{Methodology}

Based on this literature review, the current study was developed to understand how creativity changes throughout the conceptual design process in engineering education through 3 research questions (see Figure 1 for summative graphic). Specifically the following research questions (RQ) were investigated.

RQ1: Does the structure of the design problem impact maximum creativity throughout the conceptual design process (idea generation, concept selection and final conceptual design)? 
This question was addressed first because of its potential to influence the remaining research questions. Next, we wanted to explore how creativity changes throughout the stages of the design process by answering the following 2 research questions:

RQ2: How does the novelty, quality, and overall creativity of a team's idea set change from idea generation to concept selection?

RQ3: Can the creativity of the final conceptual design be predicted by the best novelty, quality, or creativity of the teams' idea set during the concept generation and selection phases?

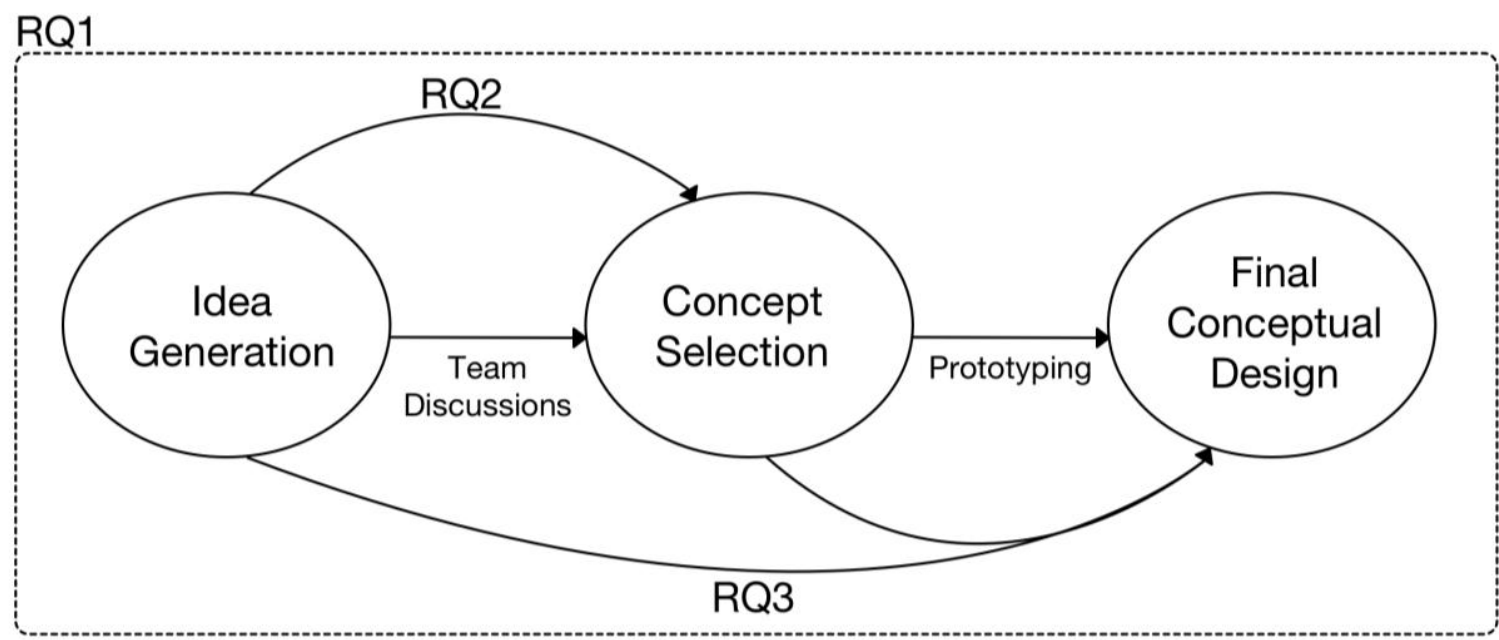

Figure 1: Research questions addressed through an empirical study with 130 engineering students.

To address these research questions, a controlled study was conducted with first year undergraduate engineering students. During the study, participants were tasked with completing an idea generation activity independently and a concept selection activity as a team. The details of this study are provided in the following sections. 


\subsection{Participants and Team Formation}

One hundred and thirty-six engineering students (100 males, 36 females) from 5 sections of the same first-year introduction to engineering design course were recruited for this study. Students in each course formed 3 and 4-member design teams that were assigned by the instructors of the course at the start of the semester based on existing knowledge and expertise in engineering design. This team formation strategy was employed in order to balance any a priori advantage of the teams through questionnaires given at the start of the semester that asked about students proficiencies in $2 \mathrm{D}$ and $3 \mathrm{D}$ modeling, sketching and the engineering design process. In total there were 36 teams including twenty-eight 4-member design teams and eight 3-member design teams.

\subsection{Procedure}

At the start of the study, the purpose and procedure of the study were discussed, any questions were answered and implied consent was obtained. Next, participants attended an in-class design session that was facilitated by the researchers, who were not the instructors of the course, to minimize instructor bias. At the beginning of this session, participants' were asked to develop novel concepts for one of three design tasks. The design tasks provided to participants were:

Milk frother ( $N=13$ teams): "Your task is to develop concepts for a new, innovative, product that can froth milk in a short amount of time. This product should be able to be used by the consumer with minimal instruction. Focus on developing ideas relating to both the form and function of the product." 
Urinary Tract Infection (UTI) test strip (N=9 teams): "Your task is to develop concepts for a new mechanism to expose test strips to urine samples. This product should be simple, inexpensive, low-waste, durable and constructed of locally-available materials to people in Northern Africa."

Greenhouse grid ( $N=14$ teams): "Your task is to develop concepts for a new tool to determine levelness of ground in a $7 x 7$ meter grid for a $6 x 6$ meter greenhouse, and to mark 49 frame post locations which are square. Any one post can be no more than 1 centimeter off and the grid should be completely marked in no more than 10 minutes. The device to measure levelness should be lightweight and ruggedized for the harsh environment in Northern Africa, with a budget of $\$ 10$. The materials are limited to nylon string, wood, and metal bars."

These design tasks were chosen for this study to represent different levels of design task structure based on their design constraints (Onarheim, 2012). The structure of a design task is not only made up of the constraints, but is also categorized based on the type of design constraints. The type of constraint was determined by its level of abstraction, which is based on whether the constraint had soft or precise limitations (Onarheim \& Wiltschnig, 2010). In the current study, the design problem was considered less structured if the constraints were abstract and/or if there were few of them, and more structured if the constraints were concrete and/or there were many of them. Based on these criteria, the milk frother task was categorized as having the least amount of structure due to its use of only abstract constraints (quick frothing, easy to use, and better than others), while the UTI test strip task was considered to have more structure due to 
the number of abstract constraints (simple, inexpensive, low-waste, durable, and limited materials). Finally, the greenhouse grid task was considered to be the most structured and constrained due to the limited number of abstract constraints (lightweight and ruggedized) and the numerous concrete constraints (accuracy, budget, and material limits) used.

Once participants read and understood their assigned design task, each participant was given individual sheets of papers and provided 20 minutes to individually sketch as many concepts as possible for their task. They were instructed to sketch only one idea per sheet of paper and write notes on each sketch such that an outsider would be able to understand the concepts upon isolated inspection, see Table 1 for example concepts.

Three hours after the brainstorming session (the next class period) participants were provided with the ideas their team developed and asked to complete the concept selection process with their team members. This process included shuffling each team's ideas, discussing each idea as a team and then categorizing each idea into one of the following categories:

Consider: Concepts in this category are the concepts that will most likely satisfy the design goals; you want to prototype and test these ideas immediately. It may be the entire design that you want to develop, or only 1 or 2 specific elements of the design that you think are valuable for prototyping or testing. 
Do Not Consider: Concepts in this category have little to no likelihood of

Table. 1 Example concepts generated and selected for the milk frother, UTI test strip, and greenhouse grid (right) design tasks.

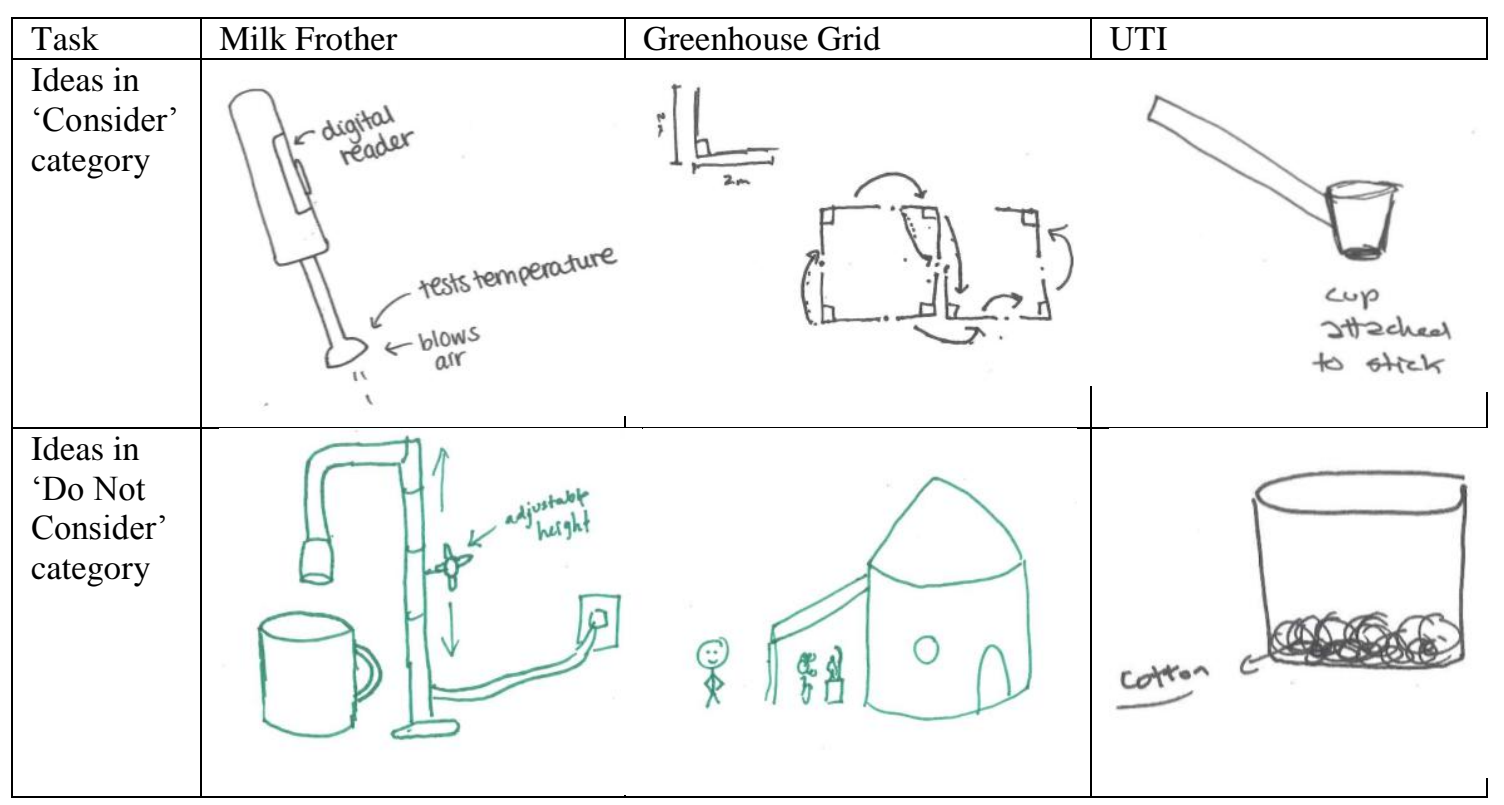

satisfying the design goals and you find minimal value in these ideas.

These designs will not be prototyped or tested in the later stages of design because there are no elements in these concepts that you would consider implementing in future designs.

These two categories were chosen for this study to simulate the rapid filtering of ideas that occur in the concept selection process (Rietzchel, et al., 2006). After the designs were classified into these two categories, the teams were then instructed to rank the ideas in the consider pile from most likely to develop (1) to least likely to develop (n) for their final conceptual design using sticky notes. The experimenters took digital pictures of the final rankings. Overall, this sorting process took approximately 30 minutes. 
Over the course of the next two weeks, the design teams created low fidelity prototypes of the chosen designs from their "consider" piles. Lessons learned from these prototypes were used to develop the final prototype that was presented in both oral and written reports. The experimenters assessed these final conceptual designs presented through these reports.

\subsection{Metrics}

Once the study was complete, the 848 ideas generated were rated for novelty and quality using Shah, et al. (2003) metrics (SVS). Novelty and quality were utilized because they can be calculated at the individual level for each idea, while the quantity and variety metrics are for use to measure groups of ideas (Oman, et al., 2013; Sarkar \& Chakrabarti, 2011). In the current study, we maintained a distinction between the novelty and quality metrics, treating them as two separate components of creativity, since the conclusions that can be drawn on how design novelty changes throughout the conceptual design process may be vastly different from the conclusions that can be drawn from how design quality changes. In addition, we also assessed the creativity of the designs as a combination of novelty and quality by adding the two measures together, each with a weight of 0.5 (Oman, et al., 2013). This was done since we are interested in ideas that possess both quality and novelty, and the combination of these two measures allow us to quickly compare the overall creativity of all designs being analyzed.

In order to calculate the SVS metrics, two raters, undergraduate students in mechanical engineering, were recruited to assess the concepts. Prior to this assessment, the raters received extensive training on the design tasks and rating process. In order to rate the designs, a Design Rating Survey (DRS) was used to help the raters classify the 
features each design concept addressed as described in (Toh \& Miller, 2016). The DRS contained 24 items for the Milk Frother design task, 14 items for the UTI Test Strip task, and 14 items for the Greenhouse Grid design task. The first set of questions on the DRS were used to help the raters classify the features each design concept addressed, similar to the feature tree approach used in previous studies used to compute design novelty (see (Toh \& Miller, 2014; Toh \& Miller, 2014) for more details). The final 4 survey questions were used to compute design quality and helped the raters identify the technical feasibility of the design. The Cohen's Kappa (inter-rater reliability) was 0.85 for the milk frother task, 0.86 for the UTI Test Strip task, and 0.78 for the Greenhouse Grid task. Any disagreements were settled in a conference between the two raters. The DRS surveys are available at (website blank for review).

In order to compare idea creativity throughout the design process, the best novelty, quality, and creativity of the teams' idea set were calculated for each of the three phases (idea generation, concept selection and final conceptual design) using the ratings from the DRS. While average novelty and quality are the metrics typically utilized in creativity literature (see for example, (Rietzschel, et al., 2006; Shah, et al., 2000; Toh \& Miller, 2014), best novelty and quality measures the possibility of attaining the maximum novelty and quality score (Vargas Hernandez, et al., 2010). This is of interest in the current investigation because ultimately, for a design team to be successful, a team only needs one very high quality, functional or novel idea, not dozens (Viswanathan \& Linsey, 2010). In addition, the goal of idea generation rarely is to maximize the average novelty or quality of an idea, but rather to maximize the novelty and quality of the best idea or the 
few best ideas (Girotra, et al., 2010). Therefore, best novelty, quality, and creativity are investigated. This section outlines how these metrics were computed.

Idea Novelty: Novelty is the "measure of how unusual or unexpected an idea is compared to other ideas" ( Shah, et al., 2003, pg 117). In order to calculate novelty at the team level, the individual novelty of each idea must first be computed. This was accomplished using the feature tree approach developed by Shah, et al. (2003) where the novelty of each individual feature is used to compute the overall novelty of the design. Specifically, feature novelty, $f_{i}$, is defined as the novelty of each feature, $i$, as it compares to all other features incorporated by all the generated designs. The more frequently a feature is incorporated, the lower the feature novelty score. We compute $f_{i}$ as shown in Equation 1:

$$
f_{i}=\frac{T-C_{i}}{T}
$$

Where $\mathrm{T}$ is the total number of designs generated by all participants and $C_{i}$ is the total number of designs that incorporate feature $i$. Feature novelty, $f_{i}$, varies from 0 to 1 , with the most novel features approaching 1 .

Design novelty of team $k$ 's $j$ th idea, $D_{j, k}$, can then be calculated based on the combined effect of the Feature Novelty, $f_{i}$, of all the features that the design addresses. Because $D_{j, k}$ is computed for all the features addressed by a design, the novelty per design is computed as an average of feature novelty, as seen in Equation 2:

$$
D_{j, k}=\frac{\sum\left(f_{i} * E_{i, j, k}\right)}{\sum E_{i, j, k}}
$$


Where $f_{i}$ is the feature novelty of feature $i$ and $E_{i, j, k}=1$ if feature $i$ addressed by team $k$ 's $j$ th idea and 0 otherwise.

Team Best Novelty $(B N V)$ : Team best novelty was developed to capture the maximum level of novelty for each team k's idea set in each design phase, p. Specifically, team best novelty metric was calculated as the highest design novelty of all the designs each team generated during each design phase (idea generation, concept selection, and final conceptual design) as previously calculated by (Vargas Hernandez, et al., 2010), as seen in Equation 3:

$$
B N V_{k, p}=\mathrm{V}\left(D_{j, k} * N_{j, k, p}\right)
$$

Where $D_{j, p}$ is the design novelty of team $k$ 's jth idea and $N_{j, k, p}=1$ if team $k$ 's $j$ th idea was being considered during phase $\mathrm{p}$ (concept generation, selection or final conceptual design) and 0 otherwise.

Idea Quality: Quality is defined as a measure of a concept's feasibility and how well it meets the design specifications (Shah, et al., 2003). In order to calculate design quality at the team level, the individual quality of each idea must first be computed. Idea quality was measured on an anchored multi-point scale similar to Linsey, et al. (2011). However, we included an additional question to the quality scale in order to capture the improvement of the generated concept over the original design for both the milk frother and UTI design task. This question was excluded from the ratings of the greenhouse grid design task since no original design was presented to the participants. The quality metric was calculated using the raters' answers to the following 3-point and 4-point scales, see Figure 2. 


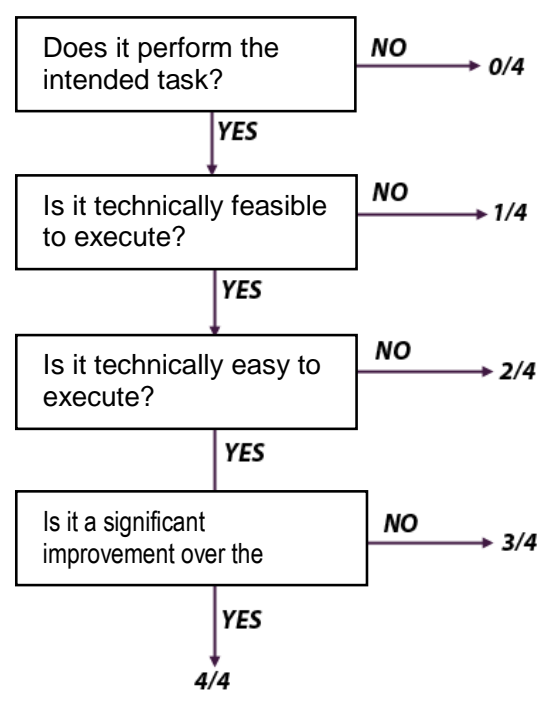

Figure 2: Quality scores assessed using the 4-point scale.

Design quality of team $k$ 's $j$ th idea, $Q_{j, k}$, was then computed using Eqn. 4.

$$
Q_{j, k}=\frac{\sum_{k=1}^{m} q_{o}}{m}
$$

Where $\mathrm{q}_{\mathrm{o}}$ is the answer to the $\mathrm{o}^{\text {th }}$ quality question, $\mathrm{q}_{\mathrm{o}}=1$ when the quality question is answered with a 'yes', $\mathrm{q}_{\mathrm{o}}=0$ when the quality question is answered with a 'no', and $\mathrm{m}$ is the total number of quality questions (4 for the milk frother and UTI tasks and 3 for the greenhouse grid task).

Team Best Quality (BQL): Similar to BNV, BQL was calculated to capture the maximum level of quality present in ideas developed by each design team. In order to accomplish this, team best quality metric was calculated as the highest design quality of all the designs each team generated (Vargas Hernandez, et al., 2010), as seen in Equation 5:

$$
B Q L_{k, p}=\mathrm{\vee}\left(Q_{j, k} * N_{j, k, p}\right)
$$


Where $Q_{j, p}$ is the design quality of team $k$ 's jth idea and $N_{j, k, p}=1$ if team $k$ 's $j$ th idea was being considered during phase $\mathrm{p}$ (concept generation, selection or final conceptual design) and 0 otherwise.

Idea Creativity: Creativity is defined as a combination of a concept's quality and novelty (Oman, et al., 2013). Similar to Oman et al. we average concept quality and novelty in order to get a creativity score with equal weights on each category.

$$
C_{j}=\frac{D_{j}+Q_{j}}{2}
$$

Team Best Creativity (BC): Similar to BNV and BQL, BC was calculated to capture the maximum level of creativity present in ideas developed by each design team. In order to accomplish this, the team best creativity metric was calculated as the highest design creativity of all the designs each team generated (Vargas Hernandez, et al., 2010), as seen in Equation 7:

$$
B C_{k, p}=\mathrm{\vee}\left(C_{j, k} * N_{j, k, p}\right)
$$

Table 2: Summary statistics for the number of ideas generated, considered and not considered for all 3 design tasks.

\begin{tabular}{|l|c|c|c|}
\hline \multicolumn{1}{|c|}{ Task } & $\begin{array}{c}\text { Milk Frother } \\
\text { Mean (SD) }\end{array}$ & $\begin{array}{c}\text { Greenhouse Grid } \\
\text { Mean (SD) }\end{array}$ & $\begin{array}{c}\text { UTI } \\
\text { Mean (SD) }\end{array}$ \\
\hline \# ideas generated & $25.62(5.09)$ & $21.71(3.50)$ & $23.44(5.55)$ \\
\hline \# ideas considered & $8.08(2.93)$ & $6.21(1.81)$ & $6.78(1.79)$ \\
\hline \# ideas not considered & $17.54(5.44)$ & $15.43(3.96)$ & $16.67(6.54)$ \\
\hline
\end{tabular}

Where $C_{j, p}$ is the design creativity of team $k$ 's jth idea and $N_{j, k, p}=1$ if team $k$ 's $j$ th idea was being considered during phase $\mathrm{p}$ (concept generation, selection or final conceptual design) and 0 otherwise. 


\section{Data Analysis and Results}

In order to address our research goals, the best novelty, quality, and creativity of ideas from the idea generation, concept selection and final conceptual design stages were analyzed. In total, 848 ideas that were developed over the course of the study were analyzed (333 idea for milk frothers, 304 for the greenhouse grid, and 211 for the UTI task), see Table 1 for sample ideas. On average, each team developed 23.56 ideas (SD = 4.8) and chose to consider $7.03(\mathrm{SD}=2.36)$ of those ideas for further development, see Table 2 for breakdown for each task. The remainder of this section presents our results with reference to our research questions. SPSS v.22 was used to analyze the results and a significance level of 0.05 was used in all analyses.

\subsection{Does the structure of the design problem impact maximum creativity throughout the conceptual design process (idea generation, concept selection and final conceptual design)?}

Our first research question was developed to understand how the structure of the design problem impacts idea creativity throughout the conceptual design process. We hypothesized that the structure of the design task would impact the creativity of designs throughout the conceptual design process, since prior work found that constraints can both limit and encourage creativity (Onarheim, 2012). Prior to answering this research question, preliminary statistical analyses were performed to determine if best novelty $(\mathrm{BNV})$, best quality (BQL), and Best Creativity (BC) were normally distributed. Because the Shapiro-Wilk's test identified that the data were not normally distributed $(\mathrm{p}<0.05)$ non-parametric Kruskal-Wallis tests were used to determine if there were significant 
differences in best novelty (BNV), best quality (BQL), and best creativity (BC) at each stage of the design process (generated ideas, selected concepts, and final conceptual designs) between the three design tasks: milk frother $(\mathrm{N}=13)$, UTI test strip $(\mathrm{N}=9)$, greenhouse grid $(\mathrm{N}=14)$, see Figure 4 . However, because each team created at least one completely feasible idea $(\mathrm{BQL}=1)$ during concept generation and selection, statistical analyses were only conducted on the final conceptual design phase for BQL. Post-hoc analyses were also performed on significant factors using Dunn's (Dunn, 1964) procedure. A corrected significance level of 0.017 was used in order to maintain a familywise error rate of 0.05 for this analysis. As a reminder, the milk frother task was considered to be the least structured task in the study followed by the UTI test strip, and the greenhouse grid task. 


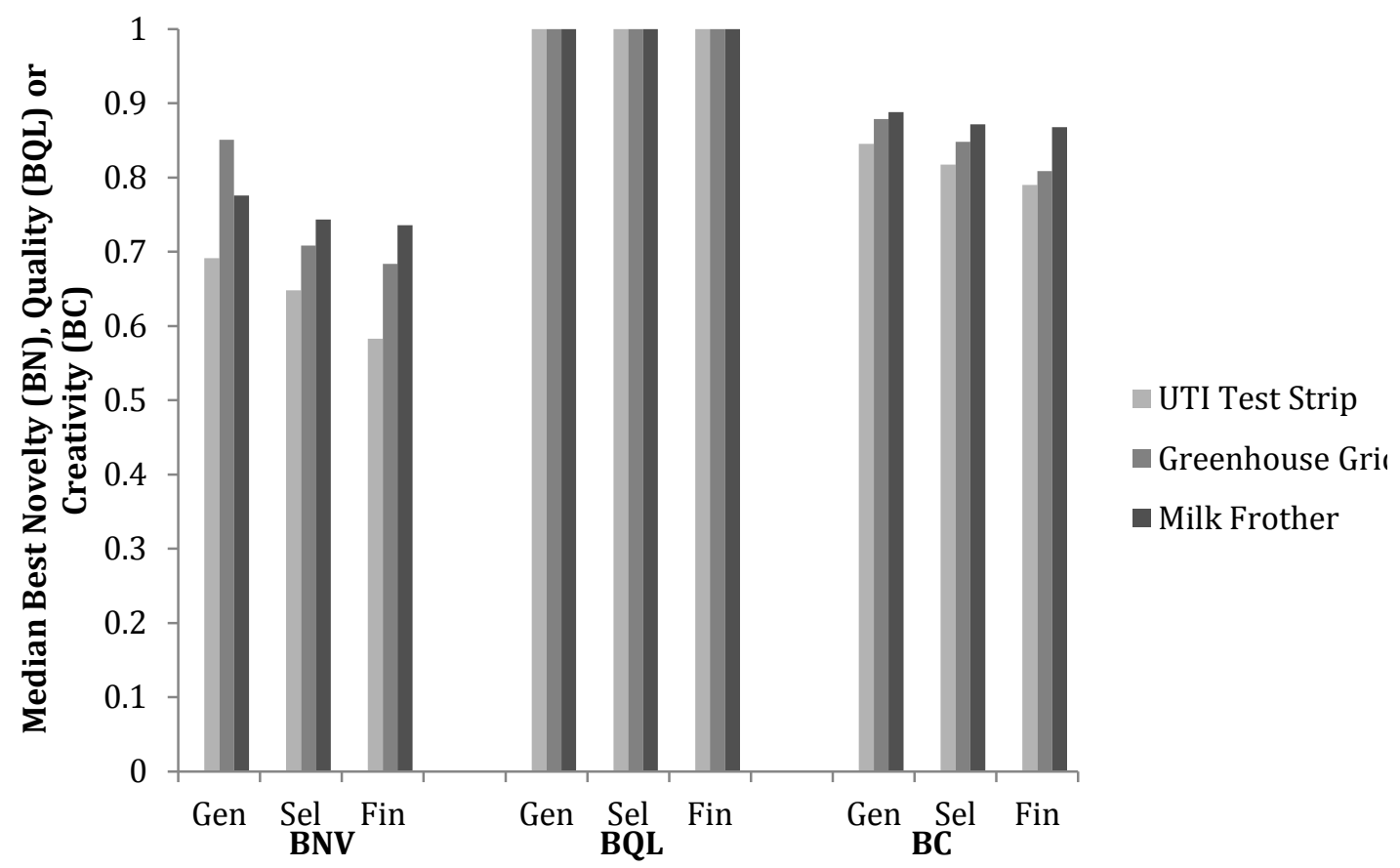

Figure 4: Best Novelty (BNV), Best Quality (BQL), and Best Creativity (BC) scores for all 3 design tasks throughout all 3 phases of the design process.

The results of the Kruskal-Wallis tests revealed that there was a significant difference in BNV across design tasks during idea generation $\left(\chi^{2}(2)=18.97, \mathrm{p}<0.001\right)$, concept selection $\left(\chi^{2}(2)=17.19, p<0.001\right)$, and final conceptual design $\left(\chi^{2}(2)=21.36\right.$, $\mathrm{p}<0.001)$. For BQL, the analysis revealed a statistically significant difference between the BQL scores of the different design tasks during the final conceptual design phase $\left(\chi^{2}\right.$ $(2)=6.73, p=0.04)$. Finally, for $\mathrm{BC}$ the Kruskal-Wallis test revealed a significant difference across design tasks during idea generation $\left(\chi^{2}(2)=13.25, p<0.001\right)$, concept selection $\left(\chi^{2}(2)=15.86, \mathrm{p}<0.001\right)$, and final conceptual design $\left(\chi^{2}(2)=21.47, \mathrm{p}<\right.$ 0.001). Post-hoc results can be found in Table 3. 
Table 3: Results of the Kruskal-Wallis tests and post-hoc analyses for BNV, BQL, and BC scores between the 3 design tasks for all 3 phases of the design process. A corrected significance level of 0.017 was used in order to maintain a family-wise error rate of 0.05 for this analysis.

Phase

\begin{tabular}{clccc} 
& & $\begin{array}{c}\text { Best Novelty } \\
(\text { BNV })\end{array}$ & $\begin{array}{c}\text { Best Quality } \\
(\text { BQL })\end{array}$ & $\begin{array}{c}\text { Best Creativity } \\
\text { (BC) }\end{array}$ \\
\hline Generated & UTI Test Strip - Greenhouse Grid & $<\mathbf{0 . 0 0 1}$ & - & $\mathbf{0 . 0 1 4}$ \\
Ideas & UTI Test Strip - Milk Frother & $<\mathbf{0 . 0 0 1}$ & - & $<\mathbf{0 . 0 0 1}$ \\
& Greenhouse Grid - Milk Frother & 0.46 & - & 0.177 \\
\hline Selected & UTI Test Strip - Greenhouse Grid & $\mathbf{0 . 0 0 2}$ & - & 0.021 \\
Concepts & UTI Test Strip - Milk Frother & $<\mathbf{0 . 0 0 1}$ & - & $<\mathbf{0 . 0 0 1}$ \\
& Greenhouse Grid - Milk Frother & 0.224 & - & 0.055 \\
\hline Final & UTI Test Strip - Greenhouse Grid & 0.024 & 0.094 & 0.823 \\
Conceptual & UTI Test Strip - Milk Frother & $<\mathbf{0 . 0 0 1}$ & 0.561 & $<\mathbf{0 . 0 0 1}$ \\
Design & Greenhouse Grid - Milk Frother & $\mathbf{0 . 0 0 8}$ & $\mathbf{0 . 0 1 2}$ & $<\mathbf{0 . 0 0 1}$
\end{tabular}

These results support our hypothesis that the design task being explored impacts the best novelty, quality and creativity of the ideas produced throughout the design process. Specifically, the greenhouse grid and the milk frother tasks only produced significantly different ideas during the final conceptual design phase, but were significant in every category (BNV, BQL, and BC), while the UTI test strip and milk frother tasks produced ideas that were significantly different during each stage for both BNV and BC. The UTI test strip and the greenhouse grid tasks produced ideas that were significantly different during idea generation for both $\mathrm{BNV}$ and $\mathrm{BC}$, and during concept selection for BNV only. These results may be due, in part, to the fact that different design tasks require different levels of creativity. These findings lend insight into how different task requirements may give students different opportunities to develop their creative thinking skills.

\subsection{How does the creativity of a team's idea set changes from idea generation to}

\section{concept selection?}

Our second research question was developed to investigate how the creativity of the teams' idea sets change from idea generation to concept selection. We hypothesized 
that the novelty of teams' ideas would decrease while the quality would increase from concept generation to selection since prior work has suggested that people are biased against novel concepts and choose more feasible concepts during the selection process (Rietzchel, et al., 2006). In order to answer our research question, ANCOVAs were used to compare team best novelty (BNV), best quality (BQL), BNV, and best creativity (BC) between the idea generation and concept selection phases while taking into account design task as the covariate due to the results from RQ1. Prior to analysis of the differences in BNV between idea generation and concept selection, all assumptions of the ANCOVA were checked. It is important to note that although the data violated the assumption of normality, the ANCOVA was still used because it is fairly robust to deviations from normality. The data presented in the remainder section are unadjusted mean \pm standard deviation unless otherwise stated.

The results of the first ANCOVA showed that there was a statistically significant difference in BNV between the idea generation $(0.77 \pm 0.07)$ and the concept selection $(0.71 \pm 0.07)$ phases $F(1,69)=17.25, p<0.001$, partial $\eta^{2}=0.20$. Specifically, of the 36 teams in the study, 29 had a decrease in BNV between these phases. The results of the second ANCOVA showed that there was a statistically significant difference in $\mathrm{BC}$ between the idea generation $(0.87 \pm 0.06)$ and concept selection $(0.84 \pm 0.05)$ phases $F(1$, $69)=5.75, p=0.019$, partial $\eta^{2}=0.08$. Specifically 23 of the 36 teams had a decrease in $\mathrm{BC}$ between the generation and selection phase. An ANCOVA was not computed for BQL scores since each of the 36 teams had at least one idea in both phases that received a maximum quality rating of ' 1 '. 
Due to the significant differences found when comparing BNV and BC between idea generation and concept selection, follow up analyses were conducted to compare $\mathrm{BNV}$ and $\mathrm{BC}$ between the ideas each team categorized into the 'consider' and 'do not consider' category in order to better understand how the idea sets are changing during this process. The results revealed a statistically significant difference in BNV between the selected concept $(0.71 \pm 0.07)$ and the not selected concepts $(0.77 \pm 0.08), F(1,69)=$ 12.532, $p=0.001$, partial $\eta^{2}=0.154$ and a marginally significant difference in BC between the selected concept $(0.84 \pm 0.05)$ and the not selected concepts $(0.86 \pm 0.05)$, $F(1,69)=3.188, p=0.079$, partial $\eta^{2}=0.044$. These results show that teams may be discarding highly novel ideas during the concept selection phase despite the quality of the idea since both the BNV and the BC decreased from idea generation to concept selection, and both the $\mathrm{BNV}$ and $\mathrm{BC}$ of the ideas selected for consideration were lower than those that were discarded. These results serve to support previous findings that found that people tend to choose feasible ideas over unique ideas because of their desire to reduce uncertainty (E. Rietzschel, et al., 2010). Since only a single highly functional and novel idea is required in order to be successful (Girotra, et al., 2010; Viswanathan \& Linsey, 2010), this early filtering of the most creative ideas may be detrimental for the creativity of the final conceptual design in engineering education.

\subsection{Can the creativity of the final conceptual design be predicted by the best novelty,} quality, or creativity of the teams' idea set during the concept generation and selection phases?

Our final research question was developed to understand if the best novelty (BNV), best quality (BQL), and best creativity (BC) of a team's idea set during idea 
Table 4: Summary of the hierarchical regression analysis results between novelty and creativity scores of the concept generation and selection stages, and creativity scores of the final design.

\begin{tabular}{lcccc}
\hline Variable & $p$ & $B$ & $S E_{B}$ & $\mathrm{~B}$ \\
\hline Intercept & 0.003 & 0.88 & 0.28 & \\
Tasks & 0.003 & 0.07 & 0.02 & 0.66 \\
BNV $_{\text {idea generation }}$ & 0.800 & -0.08 & 0.32 & -0.07 \\
$\mathrm{BNV}_{\text {concept selection }}$ & 0.456 & -0.29 & 0.38 & -0.23 \\
$\mathrm{BC}_{\text {idea generation }}$ & 0.179 & -.081 & 0.59 & -0.51 \\
$\mathrm{BC}_{\text {concept selection }}$ & 0.230 & 0.87 & 0.71 & 0.46
\end{tabular}

generation or concept selection can significantly predict the creativity of the final conceptual design. We hypothesized that creativity during both stages could be used to predict the creativity of the final conceptual design since prior research has indicated that either idea generation (Daly, et al., 2012; Duffy, 1993) or concept selection (Hambali, et al., 2009; King \& Sivaloganathan, 1999) can impact final design creativity. In order to test this, a hierarchal multiple regression analysis was run to predict the final conceptual design's creativity from $\mathrm{BNV}$ and $\mathrm{BC}$ during concept generation and selection. Since BQL was "1" for all teams at both stages of the design process, the use of BQL would not add to the model. In addition, since the design task was shown in RQ1 to play a significant role in predicting team creativity scores, the impact of creativity of the ideas developed during idea generation and chosen during concept selection on the creativity of the final designs was investigated while taking into account the effects of design task in order to 'control' for this variable. Therefore, the independent variables were entered in 2 blocks: (i) task (ii) BNV and BC during concept generation and selection.

The results of the hierarchal multiple regression analysis showed that the BNV and $\mathrm{BC}$ scores of both the idea generation and concept selection stages could not statistically significantly predict the novelty of the final conceptual design, $\left(\mathrm{R}^{2}\right.$ change $=$ 0.099 , and p-value $=0.349$ ) above and beyond the effects of task, see table 4 . These 
results indicate that the novelty of a team's final design may be predicted by the structure, or the amount and type of constraints, of the design task. However, the addition of novelty in the earlier phases of the design process did not add significantly to this prediction.

The results from the regression analysis do not support our hypothesis that novelty or overall creativity during the idea generation and concept selection phases can predict the creativity of the final conceptual design. Interestingly, these results indicate that while much engineering education research has focused on increasing creativity in the early phases of the design process (e.g. idea generation (Daly, et al., 2012; Linsey, et al., 2011; Vargas Hernandez, et al., 2014)), these efforts may not in fact impact the final conceptual design creativity.

\section{Discussion}

The current study was developed to understand how creativity changes throughout the conceptual design process in engineering education. The main findings from our study are as follows:

- Creativity in all phases of the conceptual design process in engineering education is impacted by the task being explored.

- Engineering students are discarding their most novel ideas during the concept selection process in favor of more conventional alternatives

- The creativity of student teams' idea sets during concept generation and selection cannot predict the creativity of the final conceptual design 
The remainder of this section discusses the implications of these results for engineering education with regard to task selection and creativity training.

\subsection{The Design Task Explored Impacts Creativity Throughout the Conceptual Design Process}

Our results indicate that the design task being explored affects creativity during all three phases of the design process (generated ideas, selected concepts, and final conceptual design) at the team level. This result supports prior research that showed that final design creativity is impacted by the type of task within the problem solving domain (Reiter-Palmon, et al., 2009). At the team level, students generated and selected more novel designs for the milk frother task than the UTI and greenhouse grid tasks. Given that the UTI test strip task was a moderately constrained task in relation to the other tasks, this result contradicts prior research that found that moderately constrained tasks tend to elicit the most creative designs (Joyce, 2009). In fact, while Joyce (2009) found that the most constrained and least constrained design tasks tend to elicit the least creative designs, our results show that the least constrained design task elicited the most creative designs. These results show that there is a clear difference in creativity (both novelty and quality) between tasks, but this relationship is not necessarily linear. In addition, when it came to the final conceptual design, our results showed that teams in the milk frother task had the most novel designs and, compared to the other two tasks, were the only teams to have $100 \%$ feasible designs for during the final conceptual design phase. However, the UTI and greenhouse grid design tasks were subject to more rigorous design specifications than 
the milk frother, which could cause lower creativity levels, due to the more limited solution space (Jonassen, 1997) for these design tasks.

Due to the increasing use of ill-structured design problems in the classroom (Larochelle, et al., 2004), the findings of this study lend insights into the use of different design problem structures within a cornerstone design course. Because these courses typically serve as an introduction to design for many students (Dym, 1999), these results demonstrate the importance of giving students opportunities to develop their creative thinking skills through a variety of design problems. These results also stress the importance of the thoughtful selection of design tasks that align with intended learning outcomes and goals (Thompson \& Lordan, 1999). While freshman cornerstone design courses are aimed at teaching non-discipline specific problem solving principles, students will be immersed in discipline-specific design courses as they progress through their education (Plucker, 1998). Therefore, it is crucial to continue investigating how differences in design tasks impact student learning and creativity throughout their education.

\subsection{Student Design Teams Filter out Novel Ideas but Select High Quality Ideas During}

\section{Concept Selection}

One of the key findings of this study was that student design teams were filtering out their most novel ideas during the concept selection stage of the design process regardless of the design task being explored. Specifically, we found that while the best quality of team designs remained the same throughout the idea generation and concept selection stages of the conceptual design process, the best novelty and the best creativity 
of team designs decreased throughout these stages. This decrease in best novelty and creativity while best quality remains constant indicates that design teams are filtering out not only their most novel ideas, but also their most creative (novel and quality) ideas when selecting ideas to move on in the design process.

This finding aligns with previous research that showed that designers typically choose less original ideas during concept selection (E. Rietzschel, et al., 2010) due to the uncertainty associated with choosing more novel ideas (Amabile, 1996). This is problematic since the creative potential built up during the idea generation phase is lost during the later stages (Paulus, 2000) due to the filtering of novel ideas and the lack of effective creative concept selection tools. This could be attributed to the "lock in effect", which has been studied in previous research and has been shown to keep teams from changing direction during the later stages of the design process due to the time and effort spent on developing concepts (Kiriyama \& Yamamoto, 1998). This effect can prevent design teams from modifying their ideas to increase novelty in the later stages of design, reducing the novelty of design outcomes. Another possible reason for this finding is that novice designers may perceive idea originality and feasibility as incompatible at this stage of the design process (Runco \& Charles, 1993; Sternberg, 1985), causing them to show preference for highly feasible ideas during concept selection. However, since creative ideas are widely regarded as ideas that are both novel and useful (Mumford, 2003 , p. 110) and have the potential to contribute the most value to the design process (Fuge, et al., 2013), the filtering of creative ideas can negatively affect the effectiveness of the design process. 
The findings from this study highlight the lack of emphasis on novelty during the later stages of the design process. While novelty is often emphasized during idea generation through the use of ideation tools aimed at increasing creativity, this focus on original ideas declines throughout the conceptual design process, negatively impacting the creativity of design outcomes. Therefore, further work is needed to develop improved concept selection methods that encourage student designers to select designs that are not only feasible, but also novel in the later stages of the conceptual design process. Educating student designers on the importance of selecting novel ideas in addition to feasible ideas will help increase awareness of what constitutes a creative idea and help to increase creativity throughout the design process.

\subsection{Creativity during idea generation and selection does not predict the creativity of final conceptual designs}

Much of engineering education has focused on training students to develop creative designs during idea generation with the intention of increasing the creativity of design outcomes. In addition, the concept selection stage has been emphasized as an important stage of the design process due to its influence on final design outcomes (Hambali, et al., 2009; King \& Sivaloganathan, 1999). However, our results revealed that neither the concept generation or selection stages of the design process could predict the novelty or creativity of the final conceptual design. This finding calls to question prior research that has advocated for the use of ideation tools for increasing creativity (Daly, et al., 2012; Linsey, et al., 2012), and the selection of innovative concepts during concept selection to increase the success of the final design (Huang, et al., 2013), and reveals that 
there is something other than generating and selecting ideas standing in the way of creative idea selection during the conceptual design process.

The results of our study may be attributed to factors other than idea generation and selection creativity. For instance, prototyping activities may have influenced the creativity of the final design, since all teams developed and tested prototypes of their designs between concept selection and final conceptual design phases. Surprisingly, there were 6 of the 36 teams that did not produce a fully feasible concept after prototyping, despite the fact that all teams chose at least one fully feasible concept during the concept selection phase. While teams did not necessarily prototype all of the concepts they selected, these results may indicate that prototyping did not lead all teams to develop high quality final designs. This contrasts previous work that found that prototyping improved the functionality of final designs (Kiriyama \& Yamamoto, 1998; Viswanathan, 2012) when completed during the idea generation stage (Viswanathan, 2012) (Kiriyama \& Yamamoto, 1998) indicating that the stage in which prototyping occurs may influence functionality differently. This may be due to the method of measuring design quality that relied on a 4-point scale for assessing technical feasibility and plausibility. However, future work is needed to truly understand the role of prototyping in this process.

\section{Conclusions, Limitations and Future Work}

The current study was developed in order to understand the relationship between creativity at each stage of the design process (idea generation, concept selection, final design) and to investigate the role of task on design creativity. Our results show that design task has an impact on creativity throughout the design process, and identify the importance of task selection in an engineering education. In addition, the results showed 
that engineering students may be discarding their most novel ideas during the concept selection process in favor of more conventional alternatives. This is an important finding given the importance of creativity and innovation on long-term economic success in industry. Finally, since neither the creativity of the ideas generated or selected in the current study could be used to predict the final conceptual design, it is important to explore the value of these generated/selected ideas and the factors that ultimately impact the creativity of the final conceptual design in engineering courses.

While this study identifies the importance of the design task on creativity throughout the design process, there are several limitations. First, the design task constraints were not specifically manipulated in this study leaving to question how much constraint, or what type of constraints, impact design creativity. Therefore, while this work highlights the importance of the selection of the design task for creativity learning in an engineering context, future work is needed to specifically understand the role of constraints in this process and how these constraints are perceived by students. In addition, while we looked at different types of constraints, more aspects of the structure of the design task need to be investigated to fully understand the role of the design task on creativity. However, our results provide empirical evidence for differences in novelty and creativity at all stages of the design process for different design tasks. In addition, our study was conducted with first-year engineering students. While this work highlights the impact of these criteria on engineering creativity, future work should explore the generalizability of these findings across different design domains, for different education levels, and across design industry. 


\section{Acknowledgements}

Blank for review.

\section{References}

\section{References}

Amabile, T. (1996). Creativitiy in Context. Boulder, Colorado: Westview Press. Brown, T. (2008). Design Thinking. Harvard Business Review, June 2008, 10.

Canadian Engineering Accreditation Board. (2014). 2014 Accreditation criteria and procedures. In: Engineers Canada.

Charyton, C. (2014). An Overview of the Relevance of Creative Engineering Design: Background. In Creative Engineering Design Assessment (pp. 1-10): Springer.

Daly, S. R., Yilmaz, S., Christian, J. L., Seifert, C. M., \& Gonzalez, R. (2012). Design heuristics in engineering concept generation. Journal of Engineering Education, 101, 601-629.

Duffy, A. A. (1993). Design co-ordination for concurrent engineering. Journal of Engineering Design, 4, 251-261.

Dunn, O. J. (1964). Multiple comparisons using rank sums. Technometrics, 6, 241-252.

Dym, C. L. (1999). Learning engineering: Design, languages, and experiences*. Journal of Engineering Education, 88, 145-148.

Dym, C. L., Agogino, A. M., Eris, O., Frey, D. D., \& Leifer, L. J. (2005). Engineering Design Thinking, Teaching and Learning. Journal of Engineering Education, Jan 2005.

Eling, K., Langerak, F., \& Griffin, A. (2015). The Performance Effects of Combining Rationality and Intuition in Making Early New Product Idea Evaluation Decisions. Creativity and Innovation Management, 24, 464-477.

Elsen, C., Haggman, A., Honda, T., \& Yang, M. C. (2012). Representation in Early Stage Design: An Analysis of the Influence of Sketching and Prototyping in Design Projects. In Design Engineering Technical Conferences (pp. 737-747). Chicago, IL.

Ende, J., Frederiksen, L., \& Prencipe, A. (2014). The front end of innovation: Organizing search for ideas. Journal of Product Innovation Management.

Fabien Durand, M. E. H., Joanna Tsenn, Daniel A. McAdams, Julie S. Linsey. (2015). In Search of Effective Design Problems for Design Research. In ASME 2015 International Design Engineering Technical Conferences \& Computers and Information in Engineering Conference. Boston, Massachusetts, USA.

Faure, C. (2004). Beyond brainstorming: Effects of different group procedures on selection of ideas and satisfaction with the process. The Journal of Creative Behavior, 38, 13-34.

Felder, R. M. (1987). On Creating Creative Engineers. Engineering Education, 77, $222-$ 227.

Florén, H., \& Frishammar, J. (2012). From preliminary ideas to corroborated product definitions: Managing the front end of new product development. California Management Review, 54, 20-43. 
Fuge, M., Stroud, J., \& Agogino, A. M. (2013). Automatically inferring metrics for design creativity. In ASME Design Engineering Technical Conferences. Portland, OR.

Ghosh, S. (1993). An Exercise in Inducing Creativity in Undergraduate Engineering Students Through Challenging Examinations and Open-Ended Design Problems. IEEE Transactions on Education, 36, 113-119.

Girotra, K., Terwiesch, C., \& Ulrich, K. T. (2010). Idea generation and the quality of the best idea. Management science, 56, 591-605.

Goldenberg, J., Lehmann, D. R., \& Mazursky, D. (2001). The idea itself and the circumstances of its emergence as predictors of new product success. Management science, 47, 69-84.

Goldschmidt, G., \& Tatsa, D. (2005). How good are good ideas? Correlates of design creativity. Design Studies, 26, 593-611.

Hackman, J. R. (1968). Effects of task characteristics on group products. Journal of Experimental Social Psychology, 4, 162-187.

Hambali, A., Supuan, S. M., Ismail, N., \& Nukman, Y. (2009). Application of analytical hierarchy process in the design concept selection of automotive composite bumper beam during the conceptual design stage. Scientific Research and Essays, 4, 198-211.

Harms, R., \& Van der Zee, K. (2013). Interview: Paul Paulus on group creativity. Creativity and Innovation Management, 22, 96-99.

Horowitz, R. (1999). Creative problem solving in engineering design. Tel-Aviv University.

Huang, H.-Z., Liu, Y., Li, Y., Xue, L., \& Wang, Z. (2013). New evaluation methods for conceptual design selection using computational intelligence techniques. Journal of Mechanical Science and Technology, 27, 733-746.

International Engineering Alliance. (2013). Graduate attributes and professional competencies. In: International Engineering Alliance.

Jang, J., \& Schunn, C. (2011). Physical design tools support and hinder innovative engineering design. In Human Factors and Ergnomics Society Annual Meeting. Las Vegas, NV.

Jia, L., Shaw, J., Tsui, A., \& Park, T.-Y. (2013). A SOCIAL-STRUCTURAL PERSPECTIVE ON EMPLOYEE-ORGANIZATION RELATIONSHIPS AND TEAM CREATIVITY. Academy of Management Journal, amj. 2011.0147.

Jonassen, D. H. (1997). Instructional design models for well-structured and III-structured problem-solving learning outcomes. Educational technology research and development, 45, 65-94.

Joyce, C. K. (2009). The blank page: effects of constraint on creativity. Available at SSRN 1552835.

Kabanoff, B., \& O'brien, G. E. (1979). The effects of task type and cooperation upon group products and performance. Organizational Behavior and Human Performance, 23, 163-181.

Karni, R., \& Shalev, S. (2004). Fostering innovation in conceptual product design through ideation. Information-Knowledge-Systems Management, 4, 15-33.

Kazakci, A. O., Gillier, T., Piat, G., \& Hatchuel, A. (2015). Brainstorming vs. Creative Design Reasoning: A Theory-Driven Experimental Investigation of Novelty, 
Feasibility and Value of Ideas. In Design Computing and Cognition'14 (pp. 173188): Springer.

Kelly, J. R., \& McGrath, J. E. (1985). Effects of time limits and task types on task performance and interaction of four-person groups. Journal of Personality and Social Psychology, 49, 395.

Kershaw, T. C., Peterson, R. L., McCarthy, M. A., Young, A. P., Seepersad, C. C., Williams, P. T., Hölttä-Otto, K., \& Bhowmick, S. (2015). A CROSS-

SECTIONAL AND LONGITUDINAL EXAMINATION OF THE DEVELOPMENT OF INNOVATION CAPABILITY IN UNDERGRADUATE ENGINEERING STUDENTS. In International Design Engineering Technical Conference. Boston, MA: ASME.

Kim, J., \& Wilemon, D. (2002). Focusing the fuzzy front-end in new product development. $R \& D$ Management, 32, 269-279.

King, A. M., \& Sivaloganathan, S. (1999). Development of a Methodology for Concept Selection in Flexible Design Strategies. Journal of Engineering Design, 10, 329349.

Kiriyama, T., \& Yamamoto, T. (1998). Strategic knowledge acquisition: a case study of learning through prototyping. Knowledge-Based Systems, 11, 399-404.

Koch, R., \& Leitner, K. H. (2008). The Dynamics and Functions of Self - Organization in the Fuzzy Front End: Empirical Evidence from the Austrian Semiconductor Industry. Creativity and Innovation Management, 17, 216-226.

Kornish, L. J., \& Ulrich, K. T. (2014). The importance of the raw idea in innovation: Testing the sow's ear hypothesis. Journal of Marketing Research, 51, 14-26.

Kremer, G. E., Schmidt, L. C., \& Vargas Hernandez, N. (2011). An investigation on the impact of the design problem in ideation effectiveness research. In American Society for Engineering Education Conference. Vancouver, B.C.

Larochelle, P., Engblom, J., Gutierrez, H., Larochelle, P. M., \& Larochelle, P. M. (2004). A Cornerstone Freshman Design Experience. In Proceedings of the American Society for Engineering Education (ASEE) Annual Conference \& Exposition.

Leenders, R. T. A., Van Engelen, J. M., \& Kratzer, J. (2003). Virtuality, communication, and new product team creativity: a social network perspective. Journal of Engineering and Technology Management, 20, 69-92.

Linsey, J. S., Clauss, E. F., Kurtoglu, T., Murphy, J. T., Wood, K. L., \& Markman, A. B. (2011). An Experimental Study of Group Idea Generation Techniques: Understanding the Roles of Idea Representation and Viewing Methods. Journal of Mechanical Design, 133.

Linsey, J. S., Markman, A. B., \& Wood, K. L. (2012). Design by Analogy: A Study of the WordTree Method for Problem Re-Representation. Journal of Mechanical Design, 134.

McAloone, T. C. (2007). A competence-based approach to sustainable innovation teaching: Experiences within a new engineering program. Journal of Mechanical Design, 129, 769-778.

Moscovici, S. (1976). Social influence and social change. In: London UK: Academic Press. 
Mueller, J. S., Wakslak, C. J., \& Krishnan, V. (2014). Construing creativity: The how and why of recognizing creative ideas. Journal of Experimental Social Psychology, $51,81-87$.

Mumford, M. D. (2003). Where have we been, where are we going? Taking stock in creativity research. Creativity Research Journal, 15, 107-120.

Negus, K., \& Pickering, M. J. (2004). Creativity, communication and cultural value: Sage.

Nijstad, B. A., \& De Dreu, C. (2002). Creativity and group innovation. Applied Psychology: An International Review, 51, 400-406.

Oman, S. K., Tumer, I. Y., Wood, K., \& Seepersad, C. (2013). A comparison of creativity and innovation metrics and sample validation through in-class design projects. Research in Engineering Design, 24, 65-92.

Onarheim, B. (2012). Creativity from constraints in engineering design: lessons learned at Coloplast. Journal of Engineering Design, 23, 323-336.

Onarheim, B., \& Wiltschnig, S. (2010). Opening and constraining: constraints and their role in creative processes. In Proceedings of the 1st DESIRE Network Conference on Creativity and Innovation in Design (pp. 83-89): Desire Network.

Paulus, P. B. (2000). Groups, Teams, and Creativity: The Creative Potential of IdeaGenerating Groups. Applied Psychology: An International Review, 49, 237-262.

Plucker, J. A. (1998). Beware of simple conclusions: The case for content generality of creativity. Creativity Research Journal, 11, 179-182.

Putman, V. L., \& Paulus, P. B. (2009). Brainstorming, brainstorming rules and decision making. The Journal of Creative Behavior, 43, 29-40.

Reiter-Palmon, R., Illies, M. Y., Cross, L. K., Buboltz, C., \& Nimps, T. (2009). Creativity and domain specificity: The effect of task type on multiple indexes of creative problem-solving. Psychology of Aesthetics, Creativity, and the Arts, 3, 73.

Rietzchel, E. F., Nijstad, B. A., \& Stroebe, W. (2006). Productivity is not enough: a comparison of interactive and nominal groups in idea generation and selection. Journal of Experimental Social Psychology, 42, 244-251.

Rietzschel, E., BA Nijstad, \& W. Stroebe. (2010). The selection of creative ideas after individual idea generation: choosing between creativity and impact. British Journal of Psychology, 101, 47-68.

Rietzschel, E., Nijstad, B., \& Stroebe, W. (2008). Problem scope and idea selection. In: University of Groningen, unpublished manuscript.

Rietzschel, E. F., Nijstad, B. A., \& Stroebe, W. (2006). Productivity is not enough: A comparison of interactive and nominal brainstorming groups on idea generation and selection. Journal of Experimental Social Psychology, 42, 244-251.

Rietzschel, E. F., Nijstad, B. A., \& Stroebe, W. (2010). The selection of creative ideas after individual idea generation: choosing between creativity and impact. British Journal of Psychology, 101, 47-68.

Römer, A., Pache, M., Weißhahn, G., Lindemann, U., \& Hacker, W. (2001). Effortsaving product representations in design-results of a questionnaire survey. Design Studies, 22, 473-491.

Rosenman, M. A., \& Gero, J. S. (1993). Creativity in design using a design prototype approach. Modeling creativity and knowledge-based creative design, 111-138. 
Rubenson, D. L., \& Runco, M. A. (1995). The psychoeconomic view of creative work in groups and organizations. Creativity and Innovation Management, 4, 232-241.

Runco, M. A., \& Charles, R. E. (1993). Judgements of originality and appropriateness as predictors of creativity. Personality and Individual Differences, 15, 537-546.

Sarkar, P., \& Chakrabarti, A. (2011). Assessing Design Creativity. Design Studies, 32, 348-383.

Shah, J., Kulkarni, S., \& Vargas Hernandez, N. (2000). Evaluation of idea generation methods for conceptual design: effectiveness metrics and design of experiments. Journal of Mechanical Design, 122, 377-384.

Shah, J. J., Vargas Hernandez, N., \& Smith, S. M. (2003). Metrics for Measuring Ideation Effectiveness. Design Studies, 24, 111-134.

Sternberg, R. J. (1985). Implicit theories of intelligence, creativity, and wisdom. Journal of Personality and Social Psychology, 49, 607-627.

Stokes, P. D. (2005). Creativity from constraints: The psychology of breakthrough: Springer Publishing Company.

Stokes, P. D. (2008). Creativity from Constraints: What can we learn from Motherwell? from Modrian? from Klee? The Journal of Creative Behavior, 42, 223-236.

Thompson, G., \& Lordan, M. (1999). A review of creativity principles applied to engineering design. Proceedings of the Institution of Mechanical Engineers, Part E: Journal of Process Mechanical Engineering, 213, 17-31.

Toh, C., \& Miller, S. (2014). The role of individual risk attitudes on the selection of creative concepts in engineering design. In ASME Design Engineering Technical Conferences. Buffalo, NY.

Toh, C. A., \& Miller, S. R. (2014). The Impact of Example Modality and Physical Interactions on Design Creativity. Journal of Mechanical Design, 136.

Toh, C. A., \& Miller, S. R. (2015). How engineering teams select design concepts: A view through the lens of creativity. Design Studies, 38, 111-138.

Toh, C. A., \& Miller, S. R. (2016). Choosing Creativity: The Role of Individual Risk and Ambiguity Aversion on Creative Concept Selection in Engineering Design.

Research in Engineering Design, Submitted May 2014., 1-25.

Vargas Hernandez, N., Schmidt, L. C., Kremer, G. O., \& Lin, C.-Y. (2014). An empirical study of the effectiveness of selected cognitive aids on multiple design tasks. In Design Computing and Cognition'12 (pp. 227-246): Springer.

Vargas Hernandez, N., Shah, J. J., \& Smith, S. M. (2010). Understanding design ideation mechanisms through multilevel aligned empirical studies. Design Studies, 31, 382-410.

Vetterli, C., Hoffmann, F., Brenner, W., Eppler, M. J., \& Uebernickel, F. (2014). Designing innovation: Prototypes and team performance in design thinking.

Proceedings of the 23rd International Society of Professional Innovation

Management. Barcelona. https://www. alexandria. unisg. ch/Publikationen/218901. Zugergriffen, 8.

Viswanathan, V., \& Linsey, J. S. (2010). Physical Models in Idea Generation- Hindrance or Help? In Design Engineering Technical Conferences. Montral, Quebec.

Viswanathan, V. L., JS. (2012). Physical Models and Design Thinking: A Study of functionality, Novelty, and Variety of Ideas. Journal of Mechanical Design, 134. 
Yang, M. C. (2005). A study of prototypes, design activity, and design outcome. Design Studies, 26, 649-669.

Zhang, W., Zhang, Q., \& Song, M. (2015). How do Individual - Level Factors Affect the Creative Solution Formation Process of Teams? Creativity and Innovation Management, 24, 508-524. 